We want to sort! - assessing households' preferences for sorting waste

Mikołaj Czajkowski

Tadeusz Kądziela

Nick Hanley

Stirling Economics Discussion Paper 2012-01

January 2012

Online at

http://www.management.stir.ac.uk/research/economics/workingpapers 


\title{
We want to sort! - assessing households' preferences for sorting waste
}

\author{
Mikołaj Czajkowski ${ }^{1}$ \\ Tadeusz Kądziela ${ }^{2}$ \\ Nick Hanley ${ }^{3}$
}

\begin{abstract}
There are two major ways in which solid waste can be sorted and recycled - at the household level, when households are required to sort waste into a given number of categories, or in specialized sorting facilities. Traditionally, it has been thought that sorting at the household level is an inconvenience, as it uses space and requires time and consideration. Our study provides empirical evidence to the contrary. Through a carefully designed choice experiment we collected stated choices of the members of a Polish municipalities with respect to the way their waste is sorted and how often it is collected. In the scenario of our study, respondents were informed that the waste will be sorted anyway - if not at the household level than at a specialized sorting facility. Interestingly, analysis of the preferences of members of the general public shows, that people are willing to sort waste at the household level, even if unsorted waste would be collected at no extra cost. We calculate maximum willingness to pay for collecting sorted vs. unsorted waste, as well for increased frequency of collection. Overall, our results provide encouraging evidence that most people prefer to sort waste themselves if given the choice, and thus demonstrate their pro-environment preferences, even without economic incentives to do so.
\end{abstract}

\section{JEL codes}

Q51, Q53, D12

\section{Keywords}

waste management, recycling, consumers' motives, preference heterogeneity

\footnotetext{
${ }^{1}$ University of Warsaw, Faculty of Economic Sciences, miq@wne.uw.edu.pl

${ }^{2}$ University of Warsaw, Faculty of Economic Sciences

${ }^{3}$ University of Stirling, Economics Division
} 


\section{Introduction}

Much work has been undertaken within economics to understand the determinants of household recycling behavior (Hong et al. 1993; Jenkins et al. 2003; Calcott \& Walls 2005). A positive Willingness to Pay for recycling reflects the value people place on reducing the externalities due to alternative methods of waste disposal (e.g. land fill, incineration), and possible a desire to turn "waste" into useful secondary materials. However, recycling is costly to households, both in time and effort (Huhtala 2010). In this paper, however, we show that households derive utility from the act of recycling itself, independently of impacts on the waste stream. Faced with a choice of more home sorting of waste, and a central sorting of household waste, individuals are willing to pay for waste collection options which require more time and effort on their part. This result emerges from both a simple MNL modeling of the choice data, and a more sophisticated G-MNL model with covariates in both scale and the random parameters. Using a latent class model, however, we observe that this preference for more home sorting of recyclables is restricted to one of two latent classes within the sample - albeit accounting for around $2 / 3$ rds of respondents.

\section{The existing literature - why do households recycle?}

Most of the empirical literature on participation in and choice over recycling at the household level has focused on factors that determine the direct cost to households of engaging in recycling effort such as the availability of curbside pick-up recycling rather than "bring" systems where consumers must transport recyclables to central collection points; and on the opportunity cost of not recycling as reflected by the price paid for waste collection. ${ }^{4}$

One of the earliest economic studies of recycling effort is that of Hong et al. (1993). Their sample is of 2298 households in Portland, Oregon, who could choose to participate in curbside collection schemes of household-sorted recyclables. Waste collection in the city was charged on a block-pricing scheme, with the cost to households varying with the number of bins they put out for collection. Hong et al. (1993) found that recycling effort was increasing in the waste collection fee and in levels of educational achievement, but decreasing in the cost of household time (valued mostly using the female wage rate) and was lower for home renters than home owners.

Jenkins et al. (2003) summarise findings from a number of studies following on from Hong et al. (1993) over the period 1993-2000. Their own data comes from 1,049 households in 20 US metropolitan statistical areas, and is at the level of household recycling effort. Only around $10 \%$ of these households faced a variable unit price for waste collection. Jenkins et al. (2003) note that two policy variables could impact on participation in recycling: this unit price of waste collection (the cost of not recycling), and the availability of a curbside collection scheme for recyclables. The influence of these two variables on the percentage of recycling for five different materials (glass, newspaper, plastic bottles, aluminium, yard waste and newspapers) is then estimated. They find that for all materials, presence of curbside recycling schemes increases recycling effort (this is also true for presence of a "bring" recycling scheme), but that in no case is the unit price of waste collection a significant determinant of recycling effort, unlike the findings of Hong et al. (1993) Jenkins et al. (2003) explain this lack of price effect as being likely due to the waste collection fee being tow low relative to the opportunity cost of time spent separating recyclables. They also note mixed findings in the literature on the significance of waste collection fees for recycling effort (e.g. Fullerton and

\footnotetext{
${ }^{4}$ Other factors investigated include the opportunity to recycle using deposit-refund schemes (see Calcott and Walls (2005) for a theoretical analysis of such options relative to curbside recycling).
} 
Kinnaman (1996) find no response for US households, whilst Hong (1999) finds a significant response for Korean households).

Stated preference methods have also been used to investigate household willingness to pay for the provision of recycling schemes. Huhtala (2010) reports results from an earlier study undertaken by the author in Finland, which collected 1131 responses to a contingent valuation questionnaire of WTP for alternative future waste management options for Helsinki, namely more recycling or more incineration. She found WTP for recycling to be decreasing in household income, which she attributes to the higher opportunity costs of time for high-income households, given that time must be spent in sorting waste for recycling.

Most of the studies noted above use the availability of curbside collection and waste pricing, along with household characteristics such as income, household size, education and home ownership, to explain household choice over recycling effort. However, a desire to promote an external image or internal feel-good factor may also be important. Waste management strategies which rely on appealing to households' social responsibility to increase recycling efforts impose costs on households in terms of time (Bruvoll \& Nyborg 2002). Such policies appeal to the desire of individuals to promote their self- or externally-perceived reputation or image. Increasing awareness of the social benefits of recycling can be expected, in this model, to increase household recycling actions, since this increases their self-image value, although at an increasing marginal private cost. Bruvoll and Nyborg (2002), in a survey of 1162 Norwegian citizens, find that the most frequently cited motivation for home sorting of recyclables was "I should do what I want others to do", with "I want to think of myself as a responsible person" as the second most highly reported reason. Bruvoll and Nyborg (2002) found that a sample of Norwegian households "..prefer to leave the recycling to others" (p.4) - that is, prefer separation of recyclables by others rather than by themselves.

Finally, another strand of the literature has investigated the extent to which indicators of social capital and community norms influence recycling behaviour. Kurz et al. (2007) show that a proxy for "sense of community" is closely related to engagement with recycling in Northern Ireland; whilst Videras et al. (2012) find that, for a sample of 452 US households, intensity and strength of social ties, and pro-environment community norms, are linked to recycling behaviour: "...individuals who have strong connections with neighbours and who think most neighbours do things to help the environment are more likely to recycle" (p.42). Links to "green" family networks also make recycling behaviour more likely.

Summing up the literature discussed above, participation in household recycling schemes can depend on the price of not recycling, the availability and private cost of recycling, aspects of social capital, and desires for a better self-image. We now describe the design of a choice experiment where we investigate choices over household-based recycling in Poland, focusing on the question as to whether people prefer to engage in private recycling effort rather than "leaving the recycling to others", to borrow a phrase from Bruvoll and Nyborg (2002).

\section{Case study}

The site of our survey was the municipality of Podkowa Leśna, which is considered to offer amongst the highest quality housing in Warsaw, the capital and the largest city of Poland, especially with respect to environmental amenities (such as gardens, parks, forests). Our study was designed to provide support for the municipal authorities which are currently considering the reform of the system of collecting and payments for waste, while at the same time ensuring compliance with EU 
Landfill Directive (1999/31) over reductions in landfilling; ${ }^{5}$ and the EU Waste Framework Directive (2008/98) on reaching minimum target levels of recycling. ${ }^{6}$

At the time of our study (summer 2011), the municipality of Podkowa Leśna, was inhabited by 3739 people in 1605 households. There were 12 private companies licensed to collect and transport waste, about half of them active. It was at each households' discretion whether to sign an agreement with one of the companies to collect their waste. Some of these companies collect household waste sorted (into 2 to 5 types) while others collect unsorted waste and choose to sort it later (sorting municipal waste is required by law since the beginning of 2010, however, it is not specified in law how this sorting should be taking place). Similarly, the companies differ in how many times (different types of waste) are collected per month, ranging from once a week to once a month.

\section{Experimental design and data collection}

In selecting the most preferred alternative (one of the available contracts for their waste to be selected) respondents had to consider the following attributes that we used to design our choiceexperiment study:

- number of categories waste needs to be sorted to $(1,2,5)$;

- number of times a month waste is collected $(1,2,4)$;

- cost.

The number of categories ranged from 1 (no sorting required), through 2 (recyclables, nonrecyclables) to 5 (paper, glass, metals, plastic, other). The respondents were informed, however, that in either case the collected waste would undergo a screening process, and due to regulatory requirements, even if it was collected unsorted it would still be sorted in the central professional sorting facility. The survey also reminded, that sorting into more categories required more space in the household and could be done at a different time and effort cost. The lower frequency of collecting waste requires that waste is stored on respondent's property longer but may also be associated with different cost of collection. The last attribute was monetary - total cost collecting waste from household. All levels of the attributes used in our study (including cost) were derived from observing the range of current practices of waste-collecting companies operating in Podkowa Leśna.

Experimental design consisted of 6 choice-tasks of 3 alternatives per respondent; there were 4 questionnaire versions (blocks). Our study used d-efficient Bayesian design (Ferrini \& Scarpa 2007). The priors for utility function coefficients were derived from a pilot survey. We assumed normally distributed coefficients with standard deviations equal to 0.25 of each parameter. An example choice card (translated) is presented in Figure 1.

The survey was preceded with a pilot study which allowed to test the survey, collect respondents comments and obtain priors of the parameter estimates. The main study was administered by mail. The questionnaire was mailed to every one of the 1605 households in Podkowa Leśna along with a return envelope with a stamp. We received 311 responses resulting in a response rate of nearly $20 \%$. This response rate may be considered exceptionally high for mail surveys in Poland when compared to other surveys (e.g. Markowska \& Żylicz 1999), possibly because the inhabitants of the Podkowa

\footnotetext{
${ }^{5}$ This sets targets for reductions in the percentage of biodegradable municipal sold waste disposed of to landfill by 2010, 2013 and 2020 (Polish Government 2010)

${ }^{6}$ Article $11(2)$ of the Waste Framework Directive requires Member States to take the necessary measures to achieve a target of $50 \%$ by weight by 2020 of the preparing for re-use and the recycling of waste materials such as paper, metal, plastic and glass from households.
} 
Leśna municipality are better-than-average educated and the survey dealt with local issues. The main socio-demographic characteristics of the sample did not significantly differ from the average for the municipality.

\section{Methods - discrete choice modelling}

In a random utility framework, used to analyse respondents' preferences based on their stated choices, respondent $i$ 's utility associated with choosing alternative $j$ is:

$$
U_{i}(\text { Alternative }=j)=U_{i j}=\boldsymbol{\beta}^{\prime} \mathbf{x}_{i j}+\varepsilon_{i j} \text {. }
$$

By introducing the error term it is assumed that utility levels are random variables, as it is otherwise impossible to explain why apparently equal individuals (equal in all attributes which can be observed) may choose different options.

Random utility theory is transformed into different classes of choice models by making different assumptions about random term. In order for the random component to represent the necessary amount of randomness into respondents' choices its variance needs to be sufficiently large or, since utility function has no scale, assumptions with respect to the random term variance may be expressed by scaling the utility function in the following way:

$$
U_{i j}=\sigma \boldsymbol{\beta}^{\prime} \mathbf{x}_{i j}+\varepsilon_{i j}
$$

For this model to be identifiable, however, the scale needs to be related to the inverse of the error term, $\sigma \sim 1 / \varepsilon$.

When random component of the utility function is conveniently assumed to be distributed independently and identically (iid) across individuals and alternatives - Extreme Value Type 1 distribution - a Multinomial Logit Model (MNL) is derived, with the following closed-form expression of the probability of choosing alternative $j$ from a set of $J$ available alternatives:

$$
P(j \mid J)=\frac{\exp \left(\boldsymbol{\beta}^{\prime} \mathbf{x}_{i j}\right)}{\sum_{k=1}^{J} \exp \left(\boldsymbol{\beta}^{\prime} \mathbf{x}_{i k}\right)} .
$$

The MNL model implausibly assumes not only that the random term is independent and identical for all choices and respondents but also that all respondents have the same preferences (and so the same coefficients in their utility functions, $\boldsymbol{\beta}$ ). The state-of-practice methods of relaxing these assumptions, i.e. allowing for some level of (unobserved) preference heterogeneity and possibly correlations between the alternatives and choice situations, include the Random Parameters Model (RPL).

In RPL the utility function becomes:

$$
U_{i t j}=\sigma \boldsymbol{\beta}_{i}^{\prime} \mathbf{x}_{i t j}+\sigma \boldsymbol{\Omega}_{i j} \mathbf{Y}_{i t j}+\varepsilon_{i t j}
$$


Note that parameters of utility functions are now respondent-specific. It is assumed that they follow distributions specified by a modeller: $\boldsymbol{\beta}_{i} \sim f\left(\mathbf{b}+\boldsymbol{\Delta} \mathbf{z}_{i}, \boldsymbol{\Sigma}+\boldsymbol{\Gamma} \mathbf{z}_{i}\right)$, with means $\mathbf{b}$ and variance-covariance matrix $\boldsymbol{\Sigma}$. In addition, it is possible to make means and variances of the distributions a function of observable respondent or choice-specific characteristics $\mathbf{z}$.

Even though the RPL model allows for a lot of flexibility in modelling respondents preference heterogeneity, if no correlations between random variables are allowed, all respondents are assumed to have the same scale coefficient used for normalizing their utility function, i.e. their choices demonstrate the same extent of randomness (Train \& Weeks 2005). A method which allows control for both preference and scale heterogeneity of respondents at the same time is the Generalized Multinimial Logit Model (G-MNL) (Fiebig et al. 2010). In this model, the utility function takes the form:

$$
U_{i t j}=\left[\sigma_{i} \mathbf{b}+\gamma \mathbf{z}_{i}+(1-\gamma) \sigma_{i} \mathbf{z}_{i}\right]^{\prime} \mathbf{x}_{i t j}+\omega_{i t j}
$$

Similarly to the RPL model, the coefficients in the utility function are individual-specific. Unlike in the $\mathrm{RPL}$, however, the scale coefficient is now also individual-specific (it is normalized to the mean level in the sample, see discussion below). In addition, the new coefficient $\gamma \in[0,1]^{7}$ controls how the variance of residual taste heterogeneity varies with scale. If $\gamma=0$ the individual coefficients become $\beta_{i}=\sigma_{i} b+z_{i}$, while if $\gamma=1$ they are $\beta_{i}=\sigma_{i}\left(b+z_{i}\right)$. These are the two extreme cases of scaling (or not scaling) residual taste heterogeneity in the G-MNL model (type I and type II respectively), however, all intermittent solutions are possible.

In estimation, the individual scale is usually assumed to be log-normally distributed $\sigma_{i}=\exp \left(\bar{\sigma}+\tau \varepsilon_{0 i}\right), \varepsilon_{0 i} \sim N(0,1)$. In order to allow for normalization it is assumed that $E \sigma_{i}=\exp \left(\sigma+\tau^{2} / 2\right)$, i.e. $\bar{\sigma}=-\tau^{2} / 2$. This way the scale is no longer fixed; instead it is assumed to follow lognormal distribution, with the new parameter $\tau$ reflecting the level of scale heterogeneity in the sample.

In this paper we apply the G-MNL model to analyse respondents' choices with respect to waste sorting options. However, we also provide contribution to the above model, by allowing for individual scale parameter to be a function of observable individual-specific characteristics $\mathbf{k}$ :

$$
\sigma_{i}=\exp \left(\bar{\sigma}+\tau \varepsilon_{0 i}+\boldsymbol{\theta}^{\prime} \mathbf{k}_{i t}\right) .
$$

This way we are able to observe which groups of respondents make more deterministic, and which groups - more random choices.

\section{Results}

In what follows we present the results of three econometric approaches to model consumers' behaviour. As a starting point for further analysis, we present the results of a simple Multinomial Logit Model (MNL). This is followed by the state-of-the-art approach to account for consumers'

${ }^{7}$ To assure $\gamma \in[0,1]$ it is usually modeled as $\gamma=\frac{\exp \left(\gamma^{*}\right)}{1+\exp \left(\gamma^{*}\right)}$, and it is $\gamma^{*}$ that is estimated. 
preference and scale heterogeneity, a Generalized Multinomial Logit Model (G-MNL). In order to gain a better understanding of what the structure of respondents' preferences is we also included some of the respondents' observable characteristics as covariates in their utility function parameters. Finally, we report the results of a Latent Class Model, which we use to reveal that there are two latent groups of respondents who have almost reverse preferences towards recycling.

Each of the following model was estimated in the pre-release of NLogit 5.0, using 2000 random draws. Where applicable, we accounted for the pseudo-panel structure of our dataset (since each respondent faced 6 choice-sets), by including an additional random term for all observations from the same individual.

\subsection{Multinomial Logit Model}

In the MNL model, we assumed that each respondent's utility function associated with choosing alternative $j$ was a linear function of its sort, time, and fee attribute levels representing:

- sort2, sort5 - the number of categories waste needs to be sorted to ( 2 or 5 levels, dummycoded, no sorting used as a reference level);

- time2, time4 - the number of times waste gets collected per month ( 2 or 4 , dummy-coded, 1 used as a reference level);

- fee - the monthly cost of collecting waste per household (in PLN/100).

As a result the underlying utility function was of the following form:

$$
U_{i j}=\beta_{\text {sort } 2}^{\prime} \cdot \text { sort }_{j}+\beta_{\text {sort } 5}^{\prime} \cdot \text { sort }_{j}+\beta_{\text {time } 2}^{\prime} \cdot \text { time } 2_{j}+\beta_{\text {time } 5}^{\prime} \cdot \text { time } 5_{j}+\varepsilon_{i j}
$$

The results of a MNL model are reported in Table 1. All explanatory variables turn out to be significant determinants of choice. Although the coefficient values cannot be directly interpreted, their signs and relative values reflect how different factors influence respondents' choices (their utility, and hence the probability of choosing a certain alternative). Perhaps surprisingly, the results of this basic model show that, ceteris paribus, respondents prefer to sort their waste themselves, and prefer to sort into 5 categories over 2, and 2 over no sorting. It is also preferred to have waste collected 4 times a month over 2 times a month, and 2 times a month over once a month. As expected, the utility function coefficient associated with the price of collecting waste is negative.

The MNL formulation is usually a starting point for most choice experiment models, however, it has some important limitations, arising mainly from rigid assumptions about the distribution of the error term and preference homogeneity, as discussed in section 5 . We demonstrate below how these limitations can be overcome by relaxing some of the model's rigid assumptions using the G-MNL model.

\subsection{Generalized Multinomial Logit Model}

In the G-MNL model each respondent's utility was assumed to be a linear function of the same alternative-specific attribute levels, however unlike in the MNL model, we now allowed each of the utility function coefficients to follow a normal distribution, to account for unobserved preference heterogeneity. Therefore, for each utility function coefficient associated with one of the attribute levels we now provide an estimate of mean and standard deviation of its distribution. In addition, in order to observe individual heterogeneity of respondents' preferences, we introduced individualspecific covariates to means of these distributions. These covariates are mostly representing 
respondent's current practices in dealing with household waste. In the final version of the model, in which only the statistically significant covariates were retained, the following covariates were used:

- sqsorta-dummy taking a value of 1 for respondents who currently sort all their waste ${ }^{8}$;

- sqsortp - summy taking a value of 1 for respondents who currently sort part of their waste ${ }^{9}$;

- inc-respondent's household income (in PLN/1000) ${ }^{10}$;

- price - current monthly cost of collecting household waste (in PLN/100); ${ }^{11}$

- compost - having a compost bin on respondent's property. ${ }^{12}$

In mathematical notation, we now allowed the $\beta$ s to be random variables following normal distributions, with additional covariates in each variable mean:

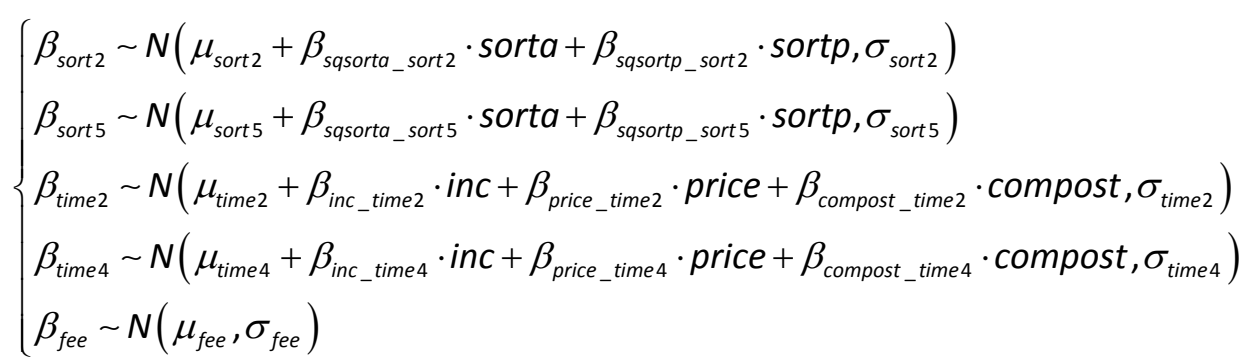

In addition, we allowed for unobservable scale heterogeneity - scale was also modelled as a random variable, as explained in Section 5. Finally, to gain a better insight into respondents' choices, we made each respondent's scale coefficient a function of his education level (edu was a dummy variable for having a university-level degree and it entered as a covariate of scale). ${ }^{13}$ As a result the individual scale coefficient was modelled as:

$$
\sigma_{i}=\exp \left(\bar{\sigma}+\tau \varepsilon_{0 i}+\beta_{e d u} \cdot e d u_{i}\right)
$$

The results of the G-MNL model are presented in Table 2 . We start the analysis by noting that the new model, allowing for unobserved and observed preference and scale heterogeneity provides a substantially better fit, in terms of pseudo- $\mathrm{R}^{2}$ and normalized AIC, than the more-restrictive MNL model. The results reveal that there was substantial preference heterogeneity among our respondents with respect to choice attributes, as illustrated by relatively high values and high statistical significance of coefficients associated with their standard deviations (column 4 of Table 2); the values not statistically different from 0 would indicate that the variables should be modelled as constants, which was not the case.

Turning to the analysis of means, we start by noting that value of their coefficients should be interpreted together with the coefficients for their covariates. The resulting picture indicates that the respondents who do not currently sort all or part of their waste ( $\operatorname{sorta}=0$ and sortp $=0$ ) have substantially lower coefficients for sorting waste into 2 or 5 categories than respondents who currently do sort their waste. In fact, the coefficient for sorting waste into 5 categories is negative, indicating that having to sort into that many categories would be worse than no sorting, these results are not statistically significant however. In contrast, respondents who currently sort waste seem to prefer sorting into 2 categories over no sorting, and sorting into 5 categories over sorting into 2 .

\footnotetext{
${ }^{8} 51.28 \%$ of respondents stated that they currently sort all their waste

${ }^{9} 28.74 \%$ of respondents stated that they currently sort part of their waste

${ }^{10}$ Respondents' mean household income was 9174 PLN

${ }^{11}$ Mean monthly cost of collecting waste was 57.02 PLN per household

${ }^{12} 63.68 \%$ of respondents stated that they currently have a compost bin on their property

${ }^{13} 68.93 \%$ of respondents declared that they have a university-level degree
} 
Interestingly, even though there seem to be no differences in their preferences towards sorting into 2 categories, those respondents who currently sort all their waste are much more in favour of sorting into 5 categories than respondents who declare that they currently sort only part of their waste, as indicated for value of covariates sorta and sortp for variables sort 2 and sort5.

The preferences towards frequency of waste collection were less differentiated. In general the respondents preferred to have waste collected more often. We observed, that respondents whose household income was higher, who currently paid higher prices for waste collection and who currently had a compost bin on their property had a stronger preferences for more frequent waste collection. Lastly, we note that the monetary coefficient - the monthly fee associated with a particular waste collection alternative, was negative. This variable also proved to be highly differentiated within our sample, indicating a high level of heterogeneity with respect to the marginal utility of income.

By utilizing the G-MNL model we were able to allow for scale coefficient to be non-constant, i.e. allowing for a different level of randomness in respondents choices. This proved to introduce a significant improvement in our model, as illustrated by a high value and high statistical significance of the coefficient $\tau$, representing the level of differentiation between respondents scale coefficients. Finally, we note that allowing for observable utility function scale differences, associated with respondents' education level, was also a significant component of the model. We found that respondents having a university-level degree had on average lower scale coefficients, hence resulting in higher variance of their responses. The rest of respondents were more deterministic in their choices, possibly following simpler (or even non-compensatory) decision rules, resulting in having lower scale coefficients.

\subsection{Latent Class Model}

In order to further investigate the dichotomy in preferences towards personal sorting of household waste we estimated a third model - the Latent Class Model (LCM). The model is essentially similar to random parameters model (see section 5 for details) in which the distribution of the parameters is discrete. Behaviorally, it allows to identify latent classes of respondents with distinct preferences exactly what we are after. The results of the LCM are presented in Table 3.

Using the normalized AIC we found that the model with 2 latent classes fitted the data best. The probability of class membership of each respondent in LCM is stochastic, however, the current practices in sorting (all or part) of waste in household as well as higher education were found to significantly explain membership. The model presents a worse fit than the G-MNL model, however, it allows for easier interpretation of results and provides additional insight into bimodality of respondents preferences with respect to personal sorting. To further facilitate the analysis, in what follows we constrained the parameters of time2, time4, and fee to be equal in the two classes, as they were not statistically different.

The results of the LCM shed more light to the bimodality of preferences observed in the results of the G-MNL model. The two classes of respondents consist predominantly of those who currently sort (all or part of) their waste (class 1), and those who do not (class 2). The first group (roughly $67 \%$ of respondents) has significant and positive preferences for personally sorting waste, and prefers to sort into 5 categories rather than to 2 . On the contrary, the second group does not 'enjoy' sorting themselves, at least as long as sorting would be done in the professional sorting facility anyway. In their case personal sorting would be associated with negative utility, which is easy to explain given the inconvenience caused by the time and space needed to do so. At the same time both classes 
prefer more frequent waste collection and have a negative cost coefficient. These coefficients were not statistically different between the two classes.

\subsection{Implicit prices}

Lastly, in order to illustrate the bimodality in respondents' preferences, we present implicit prices associated with the dummy-coded attribute levels, as estimated by the LCM model. The results are provided in Table 4. On average, the respondents belonging to class 1 (mostly associated with the ones who currently sort their waste) were willing to pay 45 PLN or 73 PLN for personally sorting their waste into 2 or 5 categories, respectively. On the contrary, for respondents classified as belonging to class 2 , personally sorting household waste to 2 or 5 categories would be as bad as an additional monthly cost of 10 or 26 PLN. We did not find differences between the two latent classes of respondents in terms of their preferences towards frequency of waste collection. They were, on average, willing to pay an additional 22 PLN for twice a month, and 30 PLN for each week waste pickup, in comparison to once a month waste collection.

\section{Conclusions}

Unlike Bruvoll and Nyborg (2002), we find that Polish households have a positive preference for personal recycling efforts (more home sorting of wastes), even when the alternative involves the same level of recycling actions by a third party. Bruvoll and Nyborg (2002) found that a sample of Norweigian households "..prefer to leave the recycling to others" (p.4). This is not what a significant sub-set of our sample prefer (around 62\%, based on latent class average class membership probability). Membership of this "home sorting" class is linked to existing sorting behaviour and to education.

Three possible explanations arise for this preference for home sorting amongst some respondents. First, individuals may derive utility from home sorting, possibly due to a desire to promote an environmental self-image, such as Bruvoll and Nyborg (2002) discuss. This is also potentially driven by a desire for a green external image, since recycling behaviour may be observable by neighbours or family and friends (Kurz et al. 2007). Second, individuals may believe that home sorting of wastes is more effective than collective sorting. If people believe that more "waste" should be transformed into useful secondary materials, then a belief in the superior effectiveness of home sorting over collective sorting would also motivate a preference for home sorting, even when it is privately costly in terms of time and effort. In de-briefing questions, we discovered that many respondents indeed felt that they would sort better, if they were to do this personally. Respondents mentioned separating aluminium foil cover from plastic containers of yoghurt packages, or not mixing paper with food waste which makes paper unusable; and that they do not trust the waste collecting companies to sort well. For instance, many respondents felt that their work is wasted, because collecting companies pick up their different bags with the same truck. Third, individuals may feel that they have a moral duty to self-sort recyclables, and so prefer choice options with more self-sorting. Unfortunately, the data available to us does not allow us to test which of these three options have more explanatory power. 
In conclusion, we find that a significant group of citizens prefer to sort their own recyclable materials than rely on curbside collection of un-sorted waste, despite the time and effort costs of sorting. The policy implication is that agencies which have targets for increased recycling and reducing household waste going to disposal routes such as landfilling and incineration can take advantage of preferences for home sorting by promoting awareness of the benefits of such actions, and providing resources which facilitate home sorting. However, a sub-set of respondents would need to be compensated for such actions, or face a higher opportunity cost of not sorting, for home sorting to be taken up across the whole population. 


\section{References}

Bruvoll A. \& Nyborg K. (2002). On the value of households' recycling efforts. In. Research Department of Statistics Norway, Discussion Paper No. 316

Calcott P. \& Walls M. (2005). Waste, recycling, and "Design for Environment": Roles for markets and policy instruments. Resource and Energy Economics, 27, 287-305.

Ferrini S. \& Scarpa R. (2007). Designs with a priori information for nonmarket valuation with choice experiments: A Monte Carlo study. Journal of Environmental Economics and Management, $53,342-363$.

Fiebig D.G., Keane M.P., Louviere J. \& Wasi N. (2010). The Generalized Multinomial Logit Model: Accounting for Scale and Coefficient Heterogeneity. Marketing Science, 29, 393-421.

Fullerton D. \& Kinnaman T.C. (1996). Household Responses to Pricing Garbage by the Bag. American Economic Review, 86, 971-84.

Hong S. (1999). The effects of unit pricing system upon household solid waste management: The Korean experience. Journal of Environmental Management, 57, 1-10.

Hong S., Adams R.M. \& Love H.A. (1993). An Economic Analysis of Household Recycling of Solid Wastes: The Case of Portland, Oregon. Journal of Environmental Economics and Management, 25, 136-146.

Huhtala A. (2010). Income effects and the inconvenience of private provision of public goods for bads: The case of recycling in Finland. Ecological Economics, 69, 1675-1681.

Jenkins R.R., Martinez S.A., Palmer K. \& Podolsky M.J. (2003). The determinants of household recycling: a material-specific analysis of recycling program features and unit pricing. Journal of Environmental Economics and Management, 45, 294-318.

Kurz T., Linden M. \& Sheehy N. (2007). Attitudinal and Community Influences on Participation in New Curbside Recycling Initiatives in Northern Ireland. Environment and Behavior 39.

Markowska A. \& Żylicz T. (1999). Costing an International Public Good: The Case of the Baltic Sea. Ecological Economics, 30, 301-16.

Polish Government (2010). Krajowy Plan Gospodarki Odpadami [National Plan for Waste Management]. In. Council of Ministers order no. 217, 24.12.2010.

Train K. \& Weeks M. (2005). Discrete Choice Models in Preference Space and Willingness-to-Pay Space. In: Applications of Simulation Methods in Environmental and Resource Economics (eds. Scarpa R \& Alberini A). Springer Netherlands, pp. 1-16.

Videras J., Owen A.L., Conover E. \& Wu S. (2012). The influence of social relationships on proenvironment behaviors. Journal of Environmental Economics and Management, 63, 35-50. 
Figure 1. Example of a choice card (translation)

\begin{tabular}{|c|c|c|c|}
\hline Choice Situation 1. & Alternative 1 & Alternative 2 & Alternative 3 \\
\hline $\begin{array}{l}\text { Method of sorting in } \\
\text { household }\end{array}$ & Into 5 categories & Into 2 categories & None \\
\hline Frequency of collection & Once every 4 weeks & Once every 2 weeks & Once every week \\
\hline $\begin{array}{l}\text { Monthly cost for your } \\
\text { household }\end{array}$ & 75 PLN & 50 PLN & 100 PLN \\
\hline Your choice: & $\square$ & $\square$ & $\square$ \\
\hline
\end{tabular}


Table 1. The results of the MNL model

\begin{tabular}{|c|c|c|c|}
\hline Variable & Coefficient & \multicolumn{2}{|c|}{ Standard error } \\
\hline sort2 & $0.52070^{* * *}$ & \multicolumn{2}{|c|}{0.09981} \\
\hline sort5 & $1.10643^{* * *}$ & \multicolumn{2}{|c|}{0.08155} \\
\hline time2 & $0.68328^{* * *}$ & \multicolumn{2}{|c|}{0.08624} \\
\hline time4 & $0.91921^{* * *}$ & \multicolumn{2}{|c|}{0.10375} \\
\hline \multirow[t]{5}{*}{ fee } & $-0.03063^{* * *}$ & \multicolumn{2}{|c|}{0.00155} \\
\hline & & Observations & 1371 \\
\hline & & Log likelihood & -1092.7431 \\
\hline & & $\mathrm{AIC}$ (norm.) & 1.6010 \\
\hline & & Pseudo- $R^{2}$ & 0.2717 \\
\hline
\end{tabular}

${ }^{* * *}{ }^{* *},{ }^{*}$ Significance at $1 \%, 5 \%, 10 \%$ level 
Table 2. Results of the G-MNL model

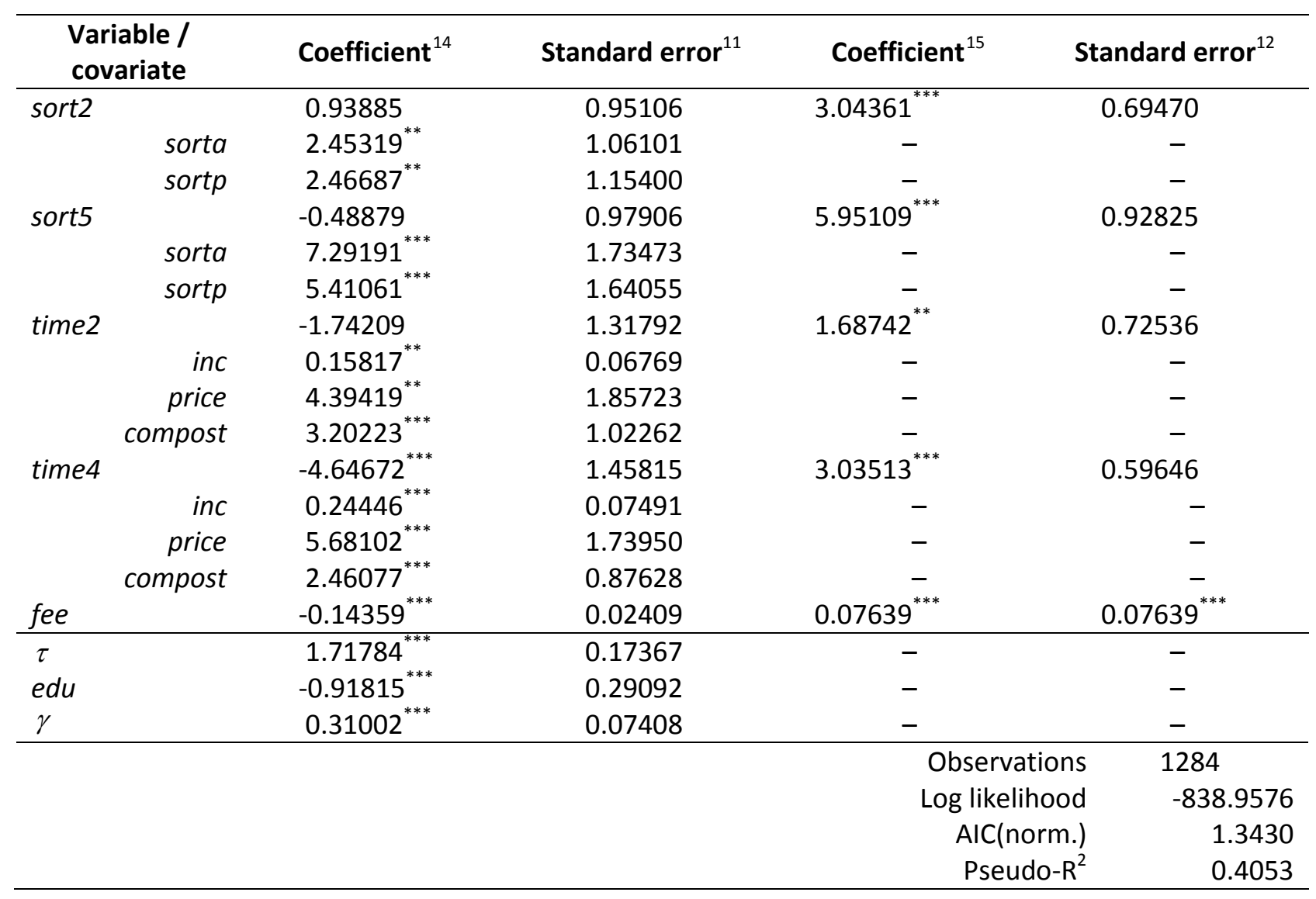

${ }^{* * *},{ }^{* *},{ }^{*}$ Significance at $1 \%, 5 \%, 10 \%$ level

${ }^{14}$ For randomly distributed coefficients - means of the distribution

${ }^{15}$ For randomly distributed coefficients - standard deviations of the distribution 
Table 3. The results of the LCM model

\begin{tabular}{|c|c|c|c|c|c|}
\hline \multirow{2}{*}{ Variable / covariate } & \multicolumn{2}{|c|}{ Class 1} & \multicolumn{3}{|c|}{ Class 2} \\
\hline & Coefficient & Standard error & Coefficient & & tandard error \\
\hline sort2 & $1.72479^{* * *}$ & 0.19814 & $-0.37800^{*}$ & & 0.19468 \\
\hline sort5 & $2.80972^{* * *}$ & 0.21613 & $-0.98502^{* * *}$ & & 0.23349 \\
\hline time2 & $0.86028^{* * *}$ & 0.10151 & $0.86028^{* * *}$ & & 0.10151 \\
\hline time4 & $1.15152^{* * *}$ & 0.12167 & $1.15152^{* * *}$ & & 0.12167 \\
\hline \multirow[t]{2}{*}{ Fee } & $-0.03827^{* * *}$ & 0.00205 & $-0.03827^{* * *}$ & & 0.00205 \\
\hline & \multicolumn{5}{|c|}{ Class membership probability variables } \\
\hline constant & $-1.42861^{* *}$ & 0.55844 & - & & - \\
\hline sort2 & $1.02602^{* *}$ & 0.46054 & - & & - \\
\hline sort5 & $2.06081^{* * *}$ & 0.44897 & - & & - \\
\hline$E d u$ & $0.89785^{*}$ & 0.47019 & - & & - \\
\hline \multirow[t]{5}{*}{ class probability } & \multicolumn{2}{|c|}{0.6680} & \multicolumn{3}{|c|}{0.3320} \\
\hline & & & Obs & & 1371 \\
\hline & & & $\log \mid$ & & -965.8914 \\
\hline & & & & & 1.4250 \\
\hline & & & & & 0.3587 \\
\hline
\end{tabular}

${ }^{* * *},{ }^{* *},{ }^{*}$ Significance at $1 \%, 5 \%, 10 \%$ level 
Table 4. Implicit prices $[\mathrm{PLN}]^{16}$

\begin{tabular}{lcccc}
\hline \multirow{2}{*}{$\begin{array}{c}\text { Attribute } \\
\text { level }\end{array}$} & \multicolumn{2}{c}{ Class 1 } & \multicolumn{2}{c}{ Class 2 } \\
\cline { 2 - 5 } \multicolumn{1}{c}{ sort2 } & Implicit price & $\begin{array}{c}\text { 95\% confidence } \\
\text { interval }\end{array}$ & Implicit price & $\begin{array}{c}\text { 95\% confidence } \\
\text { interval }\end{array}$ \\
sort5 & $45.07^{* * *}$ & $34.85-55.30$ & $-9.88^{*}$ & $-19.88-0.12$ \\
time2 & $73.43^{* * *}$ & $61.15-85.70$ & $-25.74^{* * *}$ & $-37.25--14.23$ \\
time4 & $22.48^{* * *}$ & $17.55-27.42$ & $22.48^{* * *}$ & $17.55-27.42$ \\
\hline
\end{tabular}

${ }^{* * *},{ }^{* *}{ }^{*}$ Significance at 1\%, 5\%, 10\% level

${ }^{16} \ln 20111 \mathrm{PLN} \approx 0.34$ USD $\approx 0.24$ EUR 